\title{
The London human zoo in Mark Mason's Walk the Lines. The London Underground, Overground
}

\begin{abstract}
Mark Mason's book about London documents the author's urban odyssey - his ten London walks undertaken with the aim of finding the capital's soul. The narrative key to Mason's description of London is geographical space. He walked the entire length of the Tube - overground, finding the shortest routes between each station. My paper is a proposition of negotiated reading of this journey. Instead of following the author to the sights along his walking routes, I focus my attention on his chance meetings with the people of London. Mason defines London as "the best human zoo". I explore conceptual similarities between his metaphorical human zoo and real-life $19^{\text {th }}$ and $20^{\text {th }}$-century ethnic exhibitions.
\end{abstract}

Keywords: human zoo, walker, the Tube, Mark Mason, metaphor.

Two factors have affected the choice of this topic. One was the 60th anniversary of the opening of the last European human zoo in Brussels, covered widely in the media in April 2018. The other was my son's fascination with the London underground, which prompted my choice of springtime reading that year. In an attempt to help myself communicate with a much-too-often monosyllabic teenager, I purchased Mark Mason's book advertised as a story about London and the Tube. Mark Mason is a journalist and writer and a walking tour guide in London. For a few pounds anyone can join him on a walk following a section of a selected Tube line at street level. He has also authored a number of books about Britain, which are a mix of trivia, anecdote and overheard conversation (Mason 2013a, 2015, 2017). Walk the Lines. The London Underground, Overground is a documentation of Mason's urban odyssey - his ten London walks undertaken with the aim of "finding the capital's soul" (Mason 2013b: 10). Anxious not to write

1 Address for correspondence: Faculty of Philology, University of Białystok, Plac NZS 1, 15-403 Białystok, Poland. E-mail: guzowska@uwb.edu.pl 
just another guide to London, he sought a framework to make sense of the city and found such a framework below street level. Being a keen walker, he traversed the entire length of the Tube - overground, finding the shortest routes between all 269 stations ${ }^{2}$. The project totalled 403.2 miles, 174 hours and 50 minutes over the period between June and December 2010. Observations made by the author along the way create an intricate portrait of London. He walks from station to station, but it is the world between them that interests him. He muses at the urbanscapes of particular areas, the architecture, the amount of glamour and greenery, distances from motorways, housing density, quality of shopping facilities, all the while trying to understand what gives these areas a sense of Londonness.

The following passages illustrate Mason's spirit of narrating the spaces along his routes. This one refers to the London borough of Hammersmith:

[It] feels like one of those corners of London that's trying to drag you out of the capital completely. The presence of the flyover, even when you can't see it ... pervades the whole area, never letting you entirely forget that the M4 is just a few minutes from here. So strong is the sense of westward pull that you are afraid to stand still for too long lest you be swept away, like Dorothy in The Wizard of Oz. You could be in Bristol before you know it. (127)

Many others focus on the apparent poverty or wealth of a described area: "Turnham Green is summed up by the fact that the Low Cost Mini Market has gone bust but the Himalayan Day Spa next door seems to be thriving" (288), or: "Plaistow and everywhere from here to Barking remains unglamorous, unkempt, unloved, even by those who live here" (157-158). Writing about the cityscape, the author usually chooses historical anecdotes as a means of introducing the sites to the reader. The Royal Albert Hall, for instance, is described as a venue for an indoor marathon in 1909 (287). The Tube is, obviously, often brought to the fore as a space-organizing factor in London. Mason emphasizes its role in London's territorial expansion in the $20^{\text {th }}$ century; he writes about tracks, and tunnels, stations, and roundels, enriching the story with offbeat information such as: "Maida Vale [was] the first Tube station to be manned without men: when it opened during the First World War the ticket collectors, porters and booking clerks were all female" (70).

Reading simultaneously about historical human zoos and Britain's capital city, I realized that articles about the former provided an unexpected key to interpreting the book about the latter. Although Mason's book turned out to be a rich source of facts and figures I have used to impress my 13-year-old London Tube expert, the most gripping were the occasional brief remarks on the behaviour or appearance of people, inserted

2 That was the number of Tube stations in 2010. 
into the normal spatial order of the narrative. Most were short, single sentences, frozen images, as if photographs capturing a moment. They were supposed to reflect the physical activity of walking past an object, taking a cursory glance and moving on. Then, about halfway through the book the reader comes across the following passage describing Mason's attitude to the world around him:

...Peter called it [London - D.G.] the best party on the planet, and it is, but it's also the best human zoo. 'Only connect,' E.M. Forster told us. 'Live in fragments no longer.' But some of my happiest times in London... and certainly more and more as I came to accept that this was my nature - have been spent as a fragment, watching all the other fragments. (124)

These words have become an invitation to read Mason's book, whose compositional idea is based on following the Tube lines, along alternative "human" lines. Instead of analysing the text as a guide to London, I read it as a guide to its people ${ }^{3}$. The aim of this article is thus to follow the author's thought process about these "human exhibits" and to explore the extent to which Mason's London as a metaphorical human zoo is conceptually connected with historical human zoos. What follows is a presentation of Mason's textual images of London residents and visitors juxtaposed with the findings of contemporary scholarship on $19^{\text {th }}$ and $20^{\text {th }}$-century ethnic shows and exhibitions.

Writing about the passers by Mark Mason came into contact during his London walks, he positions himself into the role of a spectator. He is, on the one hand, connected he used to be a Londoner himself; as a walker he becomes a part of the crowd around $\mathrm{him}^{4}$. On the other hand, he keeps his distance as someone who, in spite of feeling a natural bond with the subjects of his observations, chooses to stay disconnected. In many respects therefore, he resembles a $19^{\text {th }}$-century visitor to a human zoo, peering at its inhabitants as 'articles of curiosity'. However, Mason is not only a spectating walker, but also an urban travel writer, selecting stories with the greatest capacity to attract his readers. He is forced to constantly negotiate his position of a curious spectator with that of an impresario. What becomes his double objective is to enjoy the show himself as a member of the audience and also to entertain his readers with displays of individuals set against the background of the capital city. His agenda is manifestly to create a spectacle that will tell a particular story.

3 I deliberately avoid using the term Londoners here because individuals portrayed by the author are not only residents, but also tourists and visitors on business.

4 Mason does not appear to epitomize Baudelaire's flâneur "merging with the crowd" because in spite of sharing the status of an anonymous observer and being motivated by a similar curiosity, Mason, unlike a classic flâneur, does not have time and refuses to undertake an in-depth study of absorbed images of people (Baudelaire 1970: 399-400). 
"Exotic" or "monstrous" individuals had been exhibited in Europe since the Middle Ages, but rapid expansion of ethnic shows began in the middle of the $19^{\text {th }}$ century. "Savages" brought over by explorers from Africa, Asia, Australia and the Americas were displayed amidst exotic animals in elaborate "authentic" settings to entertain European audiences. The development of new media (film in particular) is credited for why Europeans lost interest in human zoos, which gradually disappeared throughout the 1930s. The world's last human zoo was organized during the World Expo held in Brussels in 1958, but it was soon closed after a series of public and diplomatic protests against racist abuse directed at Congolese artists and artisans who were brought over from Africa to perform at the fair (Kaas 2018; Abbattista \& Iannuzzi 2016). It is estimated that between 1800 and 1958, 35,000 individuals were exhibited in various kinds of human zoos; "nearly one billion four hundred million visitors were affected by this phenomenon” (Blanchard 2011: 5).

Commercial exotic displays that became elements of popular culture in the $19^{\text {th }}$ century "served as a primary vehicle for instructing a mass public about the distinctions among 'the varieties of mankind”" (Durbach 2008: 82). Mark Mason's act of observing people and their interactions seems to be following exactly the same line. It is hard to ignore his determination to see and describe the human world around him as a bizarre, varied collection of living specimens, a living cabinet of curiosities. His vision of London is that of a showcase of diversity. He makes conscious efforts to mention babies as well as centenarians, men and women, straight as well as gay couples, young professionals from the City and construction workers, Waitrose and Asda customers, those who speak Cockney and those with heavy Italian, Irish, German, or Jamaican accents. He focuses mostly on what 'meets the eye'; his kaleidoscopic picture of the people of London consists largely, though not exclusively, of his visual, rather than auditory impressions. In any case, the aim is to emphasize the wealth of cultures, races, nationalities, age and status groups. On Green Lanes in north-east London he watches two middle-aged Turkish women in traditional headscarves sit in a restaurant window making circular pide bread (Mason 2013b: 272). In the City "A Chinese man hoovers the marble floor of an office building” (314). In front of University College Hospital, on the steps of the A\&E department he catches sight of "three or four patients, one in a wheelchair, who have been sent outside to smoke" (32). On Upper Street he spots "a well-dressed woman ..., pushing a Mamas and Papas buggy containing an equally well-dressed toddler .... Balanced on top of the buggy is a punnet of ripe strawberries, which the woman eats with a white plastic fork" (35). Elsewhere he sees "a drunk in unwashed army fatigues slumped so far forward that his head nearly meets his knees" (32). Occasionally, he also resorts to eavesdropping. Outside Finchley Central on the Northern Line he hears "an Irish guy in his fifties saying to a younger Muslim woman, 'I don't want a political argument, I just think he was a very, very good painter" (234). 
Mason's human zoo is characterized by impressive plurality. However, while in the $19^{\text {th }} / 20^{\text {th }}$ century "instructing about the distinctions among the varieties of mankind" had racist undertones and was supposed to emphasize the superiority of the onlookers (Sánchez-Gómez 2013: 21), the author's approach is clearly affected by the protocols of political correctness. His metaphorical human zoo is a carefully designed product of 21st-century culture that celebrates diversity, recognizes complexity and distinctiveness of the culture of the Other, commits itself to equity and does not accept overt prejudice. Mason the impresario ensures that his audience is presented with an attractively miscellaneous assemblage of "exhibits", but he also cautiously avoids transgressing the rules of contemporary diversity discourses. Thus, in spite of their ontological difference, historical human zoos and Mason's are alike because they both serve as literal and metaphorical exhibitions of time-specific approaches to otherness.

Most of Mason's people-watching moments in London are documented in the book by brief descriptions of more or less bizarre individuals. However, the author enjoys also seeing people as parts of some collectivities or tribes, distinguishing themselves from the surroundings by their behaviour or the images they project. Similar to the communities of exotic humans in "Japanese Villages" or "Senegalese Villages" of the past, certain groups of contemporary inhabitants and visitors to London make sense to the author only when spectated in their "tribal" context. Their movements and actions are scrutinized by Mason the spectator, but there is a noticeable difference between the assumptions underlying his gaze and that of the audiences of actual human zoos. As Raymond Corbey put it pointedly: “...the natives figured as categories in Western representations of the Self, as characters in the story of the ascent to civilization, depicted as the inevitable triumph of higher races over lower ones and as progress through science and imperial conquest" (1993: 341). Mason's favourite "savages" appear to be young professionals, his juniors by around a decade or two, whom he watches with amazement mixed with nostalgia for his own passing youth. After a visit to the City he writes:

The next thing I notice is very un-Whitechapel and all the more surprising for creeping up on me so insidiously. More and more of the people passing by are young men in suits, looking not unlike young men in suits in London at any point over the last century or so, except for one thing: the vertical line of the tie is absent, replaced by the diagonal line of a bag's shoulder strap. Then it dawns on me that many of these young men are accompanied by young women, also in twenty-first-century office-casual. The couples carry shopping bags full of Sainsbury's ready meals and mid-range Merlots. ... Yes, Whitechapel is being yuppified. Not in the eighties sense of the word (braces, floppy hair, enormous mobiles), but in the strict, acronymistic sense: Young Urban Professionals. Twenty-five years ago it was Fulham. Now the tribe's more restrained members are colonizing the east. (Mason 2013b: 153-154) 
The author positions himself in the stalls, he does not join his specimens or stand next to them on stage. The tribe of young urban professionals is clearly "them", not "us", but it is the "them" that epitomizes progress, development, the future. This dichotomy becomes even more pronounced in another passage, this time set against the modern backdrop of Canary Wharf: "Smart young professionals queue at the coffee and juice outlets; a man in his fifties stands out, with his moustache and sensible coat and tweed cap. I feel an impostor too, sitting in Starbucks surrounded by a sea of iPads while I consult my paper notes about walking a Tube line" (318). The $19^{\text {th }} / 20^{\text {th }}$-century binary of wilderness and civilization, with the exhibited people in their staged tribal milieu, being the representatives of the former, is reversed in Mason's 21st-century human zoo.

The author does not altogether avoid opposition between modernity and backwardness, civilized and barbaric in its more colonial form. Writing about Westfield shopping centre, Mason allows himself a rare moment of openness in expressing the feeling of superiority at the sight of its customers. Without a trace of self-guilt and remorse he describes visitors to this "hideous", "spiritless", "grandiose”, "depressing” place in a clearly disapproving tone: "...people wander the fridge-white floors in that special slow-motion state of reverence reserved for Awesome Retail Experience" (131); or less directly: "Westfield is staggeringly, unnaturally vast, the sort of shopping 'maul' to which specially charted coach trips of middle-aged women pay pilgrimage” (117). The degree of Mason's snobbish disdain for Westfield patrons is surprising, given that he is normally very careful not to seem rude or moralistic. Paradoxically, these critical remarks appear in the only passage in Mason's book where the actual London human zoo is mentioned ${ }^{5}$. Mason's refusal to recognize Westfield as a 'natural habitat' for some Londoners and his aloofness bring him closest to the spectators in $19^{\text {th }}$ and $20^{\text {th }}$-century human zoos, reinforcing "the comfortable binary of savage/civilized that encouraged even working-class audiences to imagine themselves to be members of an imperial ruling class" (Durbach 2008: 83). The Westfield fragment of Mark Mason's narrative reveals a sense of superiority over at least some objects of his observation. This would, to some degree, explain why he found the association of London with a human zoo so appealing. Just as with European and American audiences that rendered themselves "comfortably common and safely standard" in confrontation with exotic "exhibits" (Garland-Thomson 2008: 56), Mark Mason reassures himself of his "normality" when he chooses to "walk round [Westfield] rather than through it" (Mason 2013b: 117) and when he confesses on another occasion: "Actually it would be unfair to say there isn't a single good thing about Westfield. There is: the security guard who tells me how to take a shortcut out of it" (131).

5 "Part of the site used to be the White City exhibition ground, where in 1908 the attractions at the Franco-British Exhibition included a 'Senegalese Village', inhabited by 150 Africans specially shipped in” (Mason 2013b: 117). 
Humans who were displayed in zoos were separated from the spectators by a real or imaginary barrier (Tour 2011: 7). As Raymond Corbey explains: "It was unthinkable that they [the exhibited people - D.G.] should mingle spontaneously with the visitors, and usually there were few possibilities for contact between parties" (1993: 344). Mark Mason's fantasy human zoo stretching along the lines of the Tube also features barriers. In the majority of cases they are abstract, mental walls built by the author whose nature is to be "a fragment, watching all the other fragments". In some other instances, they are very literal - panes of glass separating the spectating walker from the people he is watching. Passages relating to the latter are in fact among the most appealing in the whole book. Glimpsing through the windows of houses, hotels and offices he passes on the way, the author admits "feeling unnervingly like James Stewart in Rear Window" (Mason 2013b: 78), but he still succumbs to the temptation. What he sees and then describes are pieces of somebody else's life, tantalizingly fragmentary: "On the fourth floor a Japanese man stands immobile in trousers and a vest, fruitlessly trying to work his TV remote control. Directly underneath him an excited kid uses a bed as a trampoline" (78); or "A short row of Georgian houses have different arrangements of shutters in place. Under the top half of one set I see a couple's four hands eating chops and peas; over the bottom half of another I see a woman peeling potatoes watched by her Siamese cat, which sits on the work surface" (156). Unaware of being observed (contrary to the living exhibits in human zoos), the seen do not reciprocate Mason's gaze; their lives remain secret and unknown (just like the lives of individuals behind the fences enclosing "authentic ethnic villages" in European cities). Keeping a physical distance enforced by trenches, railings or balustrades, audiences in $19^{\text {th }} / 20^{\text {th }}$-century human zoos reduced their observation to the exterior appearance of the people on display. Unable, and possibly unwilling, to interact with the human exhibits behind the barriers, yet convinced of encountering authentic indigenous "savages", those Europeans constructed their own picture of the exotic. Their "imperial eyes" (Pratt 1992: 3) were fed with images that consolidated the stereotypical view of the colonized world as wild, uncivilized, primitive. The way Mark Mason looks at the living specimens in his human zoo is definitely not a typical objectifying "imperial gaze" as described by Ann Kaplan. Nevertheless, her thesis that "the subject bearing the gaze is not interested in the object per se, but is consumed by his own anxieties" (Kaplan 1997: xviii) can be tentatively employed to expose Mason's agenda. Like the spectators, who despite the fences blocking their interaction with the Other, flocked to "ethnic villages" in search of the authentic, Mark Mason collects the visual memories of anonymous lives enclosed by window frames in the belief that they represent London's true character.

The most successful human zoos of the past took care to balance sex and age among their "living exhibits". It was believed that "the presence of women and children made a show especially attractive and gave a better picture of 'the foreign people's family lives"” 
(Thode-Arora 2008: 169). Mason's human zoo in Walk the Lines is a perfectly balanced one. My rough estimate of the number of entries mentioning women and men reveals the author's impressive care for gender equality. Even the choice of behavioral characteristics that attract Mason's attention in male and female objects is remarkably unbiased. So, as he walks past a day spa, his eyes fall upon "A semi-reclined businesswoman [gazing] vacantly out of the window as the soles of her feet are rubbed" (Mason 2013b: 76) and then he notices a man in a nail clinic, who "sits with his hands on the desk, having for some reason crossed them over, a different woman working on each while a third squats to beautify his feet" (240). Elsewhere he overhears a mother saying: "You're really starting to piss me off!" to her toddler son (285), but to maintain his gender equilibrium he also reports passing "A man on an expensive mountain-bike calmly [reasoning] with his screaming daughter" (70). Sarcastic comments are delivered according to the rules of gender parity, too. Mason sounds acerbically when he writes: “... at Goodge Street station a woman of a certain age meets her friend, though because of the 'work' with which she's sought to deny said age, her face is incapable of expressing emotions, so a hug is all the friend gets" (217). He appears no less sarcastic when he asks a rhetorical question: "Why do people do that?" after seeing a "labourer who despite a pronounced Tennent's Tummy has chosen to tuck his T-shirt in" (194). To complete the picture, the spectacle in Mason's book is enriched by a few casual glances at children. In historical human zoos children were usually exhibited along with their parents or other adults, thus providing the "knowledge" about exotic people's caregiving practices and "supporting the idea that the exhibition illustrated an ordinary ... way of life" (Andreassen 2015: 89). Almost all children mentioned by Mason are accompanied by their parents and there is no doubt that the author's reason for selecting particular images was identical with that of human exhibition managers. Incorporating the scenes of children at play (with a trampoline, a bicycle and a home video game console), children talking or arguing with their mums and dads, children being taken care of, Mason intends to give his portrait of London's population a sense of authenticity. This is an awareness strategy which he clearly shares with Carl Hagenbeck and other $19^{\text {th }}$ and $20^{\text {th }}$-century exhibitors.

Mason remembers that in a zoo it is not only the variety on show, but also the exoticism of the specimens that seduces the public. Individuals who were selected to inhabit $19^{\text {th }} / 20^{\text {th }}$-century human zoos were supposed to appear strange to the spectators (Thode-Arora 2008: 167-168). People of unfamiliar appearance or behavior were to meet the public's expectations of arousing powerful sensations and their desire for the spectacular, novel or bizarre (Tour 2011: 10). On a visit to his London human zoo, Mason appears to be particularly alert to the incongruous, always on the lookout for oddity. Most examples of human behaviour in his book concern discrepancy between a stereotypical image and observed reality. In the following passage the author focuses on a spectacular incongruity between the subject's age and appearance: 
The traffic lights on the far side of the Palace conveniently turn red as I want to cross, halting a woman who's seventy if she's a day, sitting astride a huge 1970s Suzuki motorbike, cigarette hanging vertically from her bottom lip. Once across, I turn to see her roar away. The back of her denim jacket says: 'The Clash.' (Mason 2013b: 27)

The description of the woman's peculiar appearance is obviously supposed to add a comic touch to the narrative. As a "living specimen", it is also possible that she was to be a dramatic example of English eccentricity. Further on in the book Mason once again focuses on provoking inconsistency in image. At King's Cross the author watches passengers leaving the train: "One of the alighting passengers is a monk, wearing black robes and sandals, carrying an ultra-modern plastic suitcase in day-glo green" (33). Both the elderly woman riding a motorbike and the monk with neon accessories capture the spectator's attention because the images they present are perceived as bizarre. On other occasions, the "strangeness effect" is produced by exactly the opposite; that is, the remarkable intensity of "representativeness" or "typicality". Such an example is to be had when Mason experiences watching joggers near East Putney station on the District Line: "Among the few males of the breed are two blond late-teen twins, maintaining a frightening pace; disturbingly Aryan” (172). A similar mechanism of perception is triggered by the sight of a "builder putting on his boots in Tooley Street [and showing] the obligatory bum cleavage" (316). The word "obligatory" reveals that it is not the scene as such, but its very predictability that causes amusement, attracts attention, makes the view exotic (however self-contradictory it might appear).

In her study of human exhibitions, Rikke Andreassen indicates that "The act of describing holds an inherent power .... Those who described or staged the [human] exhibitions had the power to define the others" (2015: 3). She provides an example of African people who were often stereotypically "positioned as barbaric savages and representatives of a lower and uncivilized race" (51). This negative portrayal of the exhibited individuals was believed, paradoxically, to appeal to the white audience because of its potential to emphasize the white race's perceived superiority. The way Mark Mason handles the issue of depicting the non-white - Black and Asian - inhabitants of his metaphorical London human zoo is a vivid testimony to the monumental change that has taken place in our understanding of "the power to describe others". Mason very carefully avoids negative ethnic stereotyping and whenever he suspects that his depiction could be interpreted as prejudiced, he immediately acknowledges being too hasty in his judgements. One example of such an approach comes from the passage referring to the author's brief encounter with the inhabitants of a once shabby neighbourhood near Tottenham Hale station. It reads: "Leaving the park, I see, out of the corner of my eye, a black man talking to a friend". The author quotes the man's words verbatim to preserve the flavor of Jamaican English: 
'They is all cheesing me off, blood, innit?' he says. 'They is like > what you lookin' at?<, and I'm like $>$ I is lookin' at you, man<'. So there's at least one representative of old Tottenham still around. I wonder what trouble this homey from the 'hood has been causing. ... I turn to look at him. Instead of low-slung jeans and copious jewellery I'm confronted with a uniform and a name-badge. He's a security guard for Next. (Mason 2013b: 46-47)

Mason explains further that the man was not giving an account of "causing trouble" but of his attempt to prevent shoplifting. Hearing the strong Jamaican accent, the author had automatically identified the speaker as belonging to the group whom he subconsciously associated with "low-slung jeans and copious jewellery". However, after taking a careful look, Mason allows himself the elbow room to step back and recognize his unfair stereotypical assumptions - an activity we have almost no record of with regard to the visitors to actual human zoos in the past ${ }^{6}$.

The idea of putting "exotic" people on display has luckily been abandoned, but the concept of human zoos found an interesting reformulation in the study of Desmond Morris titled The Human Zoo published in the late 1960s. The author worked as a zoo curator in London, where he studied the lives of animals confined to small cages. It inspired him to search for parallels between animal zoos and the human cities, and what surprised him most were the similarities between abnormal behaviours of the captive zoo inmates and those of highly stressed city-dwellers. Mark Mason does not use the term human zoo in the sense proposed by Morris. His reference point is clearly the institution of historical ethnic shows as the spectacles of otherness and the sites of knowledge. Containing "examples of the rare, the curious, the strange, and the precious - all expressions of the unusual and the different" (Corbey 1993: 340), human zoos were meant to educate by means of "visual empiricism". The lesson that Mark Mason the impresario obviously wants his readers to learn is that to know London one must look at its people. His narrative points to the centrality of the gaze, the visual ${ }^{8}$. The many images of individuals of different ethnicities, sexes, ages and classes create a multicoloured vision. Mason is preoccupied with seducing the public with an attractive show, promising that in the end they will be able to repeat after Samuel Johnson that "London is the school for studying life" (Mason 2013b: 4).

The greatest disappointment is that not much more than a predictable conclusion that London's population is indeed exceptionally diverse appears to transpire from his

\footnotetext{
$6 \mathrm{H}$. Thode-Arora's analysis of late $19^{\text {th }}$-century German newspapers failed to find any negative commentaries on Hagenbeck's shows. Only a few church and missionary papers questioned the principle of putting people on display (172).
}

7 For the significance of optical/visual empiricism see: Sekula (1986).

8 For the role of visualism as a cognitive style see: Fabian (1983: 141). 
narrative. Mason does not - to quote a famous London walker Virginia Woolf - "dig deeper than the eye approves" (1930: 7). His group portrait of the people of London is visually attractive, but it is not meant to provoke any unsettling questions or challenge dominant discourses of diversity and multiculturalism. Mason's readers are presented with an account of his quest for the "soul" of London, but they soon realize that they are following the author along paths that have been well trodden. Designing his London zoo, Mason makes no random choices - every single individual who is displayed to the reading public contributes to a coherent whole. The selection of images which are supposed to represent London's diversity is very much in line with the Foucauldian suggestion concerning the essence of observation, which is systematizing, taming the unknown and turning it into an entity that can be easily analyzed, "recognized by all, and thus given a name that everyone will be able to understand" (Foucault 1994: 134). The twenty-first-century British metropolis is commonly "recognized" as a multi-ethnic and multi-cultural "entity" and Mason portrays it accordingly in Walk the Lines. Whether consciously or not, he perpetuates the dominant narrative through his authority of a London walker who has "travelled into the heart of the greatest city in the world, then back out again" (Mason 2013b: 10).

Historical human zoos provided an opportunity to demonstrate the modernity and cultural superiority of western civilization. Mark Mason's London human zoo tells the story of a population that is modern in the 21st-century sense: tolerant, cosmopolitan, non-violent, stylish, youthful, egalitarian, and whose only failing is that it succumbs easily to the allure of consumer capitalism. A conclusion that can be drawn from the reading of books such as Mason's, but also of some better known contemporary London walkers - Iain Sinclair (2003a; 2003b; 2017) or Peter Ackroyd (2000) - is that while 21st-century human zoos are no longer physical spaces in big cities, but metaphorical spaces in books about big cities, they still serve a very similar purpose, which is to mould people's imagination and influence readers' way of thinking through entertainment. The human shows of the past were meant to "persuade, deceive and manipulate [the public opinion into embracing] racism, segregation and eugenist ideas" (Blanchard 2011: 5). Their underlying objective was to justify colonization (Knox 2016: 21-22). The human zoo in works such as Walking the Lines is the spectacle of idealized multiculturalism, with the writer playing the role of an impresario guided by the goal of constructing a narrative portrait of a perfectly harmonious, postcolonial metropolis.

\section{References}

Abbattista, G.\& Iannuzzi G. 2016. World expositions as time machines: Two views of the visual construction of time between anthropology and futurama. World History Connected 13.3, 48 pars. https://worldhistoryconnected.press.uillinois.edu/13.3/forum_@1_abbattista.html (20 October 2019). 
Ackroyd, P. 2000. London. The Biography. London: Vintage.

Andreassen, R. 2015. Human Exhibitions. Race, Gender and Sexuality in Ethnic Displays. Furnham: Ashgate Publishing Ltd.

Baudelaire, Ch. 1970. Paris Spleen, trans. L. Varèse. New York: New Directions Books.

Blanchard, P. 2011. Foreword. Human Zoos: The Invention of the Savage. Exhibition Guide, Musée du Quai Branly: 5.

Corbey, R. 1993. Ethnographic showcases, 1870-1930. Cultural Anthropology. August 1993: 338-369.

Durbach, N. 2008. London. Capital of exotic exhibitions. In: P. Blanchard et al. (eds.), Human Zoos. Science and Spectacle in the Age of Colonial Empires, 81-88. Liverpool: Liverpool University Press.

Fabian, J. 1983. Time and the Other. How Anthropology Makes its Object. New York: Columbia University Press.

Foucault, M. 1994. The Order of Things: An Archaeology of the Human Sciences. New York: Vintage Books.

Garland-Thomson, R. 2008. From wonder to error: Monsters from antiquity to modernity. In: P. Blanchard et al. (eds.), Human Zoos. Science and Spectacle in the Age of Colonial Empires, 52-61. Liverpool: Liverpool University Press.

Kaplan, A. 1997. Looking for the Other: Feminism, Film, and the Imperial Gaze. New York: Routledge.

Kaas, S. 2018. The Last Human Zoo https://www.youtube.com/watch?v=v9T5NQFy0ls (20 October 2019).

Knox, K. E. 2016. Race on Display in 20 th - and 21st-Century France. Liverpool: Liverpool University Press.

Mason, M. 2015. Mail Obsession. A Journey Round Britain by Postcode. London: Weidenfeld \& Nicolson.

Mason, M. 2013a. Move Along, Please. Land's End to John O'Groats by Local Bus. London: Random House.

Mason, M. 2017. Question Time. A Journey Round Britain's Quizzes. London: Weidenfeld \& Nicolson.

Mason, M. 2013b. Walk the Lines. The London Underground, Overground. London: Arrow Books.

Morris, D. 1996 [1969]. The Human Zoo. New York-Tokyo-London: Kodansha International. Pratt, M. L. 1992. Imperial Eyes: Travel Writing and Transculturation. London: Routledge.

Sánchez-Gómez, Luis A. 2013. Human zoos or ethnic shows? Essence and contingency in living ethnological exhibitions. Culture and History Digital Journal December 2(2): 1-25. Sekula, A. 1986. The body and the archive. October 39: 3-64.

Sinclair, I. 2003a. Lights Out for the Territory. London: Penguin Books.

Sinclair, I. 2003b. London Orbital. A Walk Around the M25. London: Penguin Books. 
Sinclair, I. 2016. London Overground: A Day's Walk Around the Ginger Line. London: Penguin Books.

Sinclair, I. 2017. The Last London: True Fictions from an Unreal City. London: Oneworld Publications.

Thode-Arora, H. 2008. Hagenbeck's European tours: The development of the human zoo. In: P. Blanchard et al. (eds.), Human Zoos. Science and Spectacle in the Age of Colonial Empires, 165-173. Liverpool: Liverpool University Press.

Tour of the Exhibition. 2011. Human Zoos: The Invention of the Savage. Exhibition Guide, Musée du Quai Branly, 7-14.

Woolf, V. 1930. Street Haunting, San Francisco: The Westgate Press.

$$
* * *
$$

Dorota Guzowska is a Lecturer in British Studies and British History at the University of Bialystok. Her research is focused on the concepts of fatherhood and emotional communities in early modern England. She has published on autobiographical writing, parental identity and aspects of seventeenth-century medical care. Her interests include also: class in contemporary Britain and hegemonic discourse. 